\title{
Counter-Intentional Errors of Basketball Free Throw Shooting Under Elevated Pressure: An Educational Approach of Task Instruction
}

\author{
Recep Gorgulu ${ }^{1}$ \\ ${ }^{1}$ Elite Performance in Sport Research Group, Department of Physical Education and Sports, Faculty of Sport \\ Sciences, Bursa Uludag University, Turkey \\ Correspondence: Recep Gorgulu, Elite Performance in Sport Research Group, Physical Education and Sports \\ Department, Faculty of Sport Sciences, Bursa Uludag University, Bursa, Turkey. E-mail: \\ gorgulurecep@gmail.com
}

Received: January 10, 2019

Accepted: February 23, 2019 Online Published: February 25, 2019

doi:10.5539/jel.v8n2p89

URL: https://doi.org/10.5539/jel.v8n2p89

\begin{abstract}
The aim of this experimental study was to test Wegner's (1994) theory of ironic processes in a basketball free throw task under pressure. More specifically, Wegner (1994) predicts that when instructed not to perform in a certain manner performers' performance will break down where it is least desired way which is the main hypothesis of the current study. More specifically, it was hypothesized that when basketball players were instructed "not to throw the ball" into the certain zone on the backboard would decrease their performance in ironic fashion especially under manipulated high-anxiety condition. The sample of the present study comprised 37 male $\left(M_{\text {age }}=22.30, S D=2.89\right)$ experienced university basketball players. Participants' anxiety was measured using MRF-3 (Krane, 1994). In a basketball free-throw task; the numbers of targets, non-target non-ironic balls and ironic error balls were counted and overall performance was also calculated in order to measure participants' performance. Based on the scoring system, participants gained +5 points for throwing into the target, scored -5 points making an ironic error and 0 points for throwing the ball to anywhere (except the target and non-target ironic error zone) on the backboard. Results revealed that when instructed not to throw in a certain zone, performers' overall performance changed in ironic fashion across anxiety conditions. Findings suggest that understanding the mechanism of ironic processes of mental control theory may be a useful theoretical framework for examining the relationship between anxiety and performance in sport, physical education and motor control studies.
\end{abstract}

Keywords: basketball, pressure, performance, ironic error, physical education

\section{Introduction}

Research into the sports domain has extensively focused on determining the relationship that exists between anxiety and performance. Anxiety is postulated to occur as a result of a threat and is related to the subjective evaluation of a situation with regard to one's self-esteem (Eysenck, 1992). Findings illustrated by the vast research conducted over the years have lent support to various models and theories that aim to demonstrate the relationships that exist between anxiety and performance, such as conscious processing hypothesis (Baumeister, 1984; Masters, 1992), attentional control theory (Eysenck et al., 2007), and the catastrophe models (Hardy, 1990; Hardy, Beattie, \& Woodman, 2007; Hardy, Woodman, \& Carrington, 2004). However, these theories and models are limited to provide such details in which anxiety can elicit counter-intentional errors of sporting performance (Woodman, Barlow, \& Gorgulu, 2015). In fact, these counter-intentional errors can be more severe than general performance decrements in sport such as football penalty shooting, basketball free throw or golf putting. For example, a professional basketball player might instruct himself to avoid throwing the ball to the rim (or a specific part of the backboard), just before executing to do exactly that shot. Such unwanted (e.g., counter-intentional) errors can be explained by Wegner's (1994) theory of ironic processes of mental control as the theory describes the ironic processes of mental control that a discrepancy between the expected outcome and the actual results when enlivened by perverse appropriateness. According to Wegner's (1994) theory, there are two processes that interact with each other in order to direct an individual to the desired state of the mind. The first process is a conscious, effortful and interruptible operating process that searches for relevant signals and feedbacks to enhance the intended mental state and therefore behaviour of the individual. For instance, a 
basketball player on the free-throw line at the last second of the match would consciously search for information related to performing the last free-throw successfully. This relevant information would be the one reminding player herself the correct body position, speed and velocity of the ball from the last time she made a successful shot. Secondly, there is another process called ironic monitoring process that searches for signals that are related to the failure and specifically undesired action of mental state and behaviour. The ironic monitoring process is an unconscious, effortless and uninterruptible process. From the above example, the basketball player who stands at the free-throw line for the last free-throw of the match might be recalling the distractive funs behind the backboard or the previous bad free throw attempt that caused a bad result. Although these two processes are opposite to one another are proposed to work as a dual feedback loop under normal circumstances. However, when under mental load (e.g., time pressure, anxiety, stress, task difficulty), the ironic monitoring process may start to take over on the conscious operating process (Wegner, 1994) and therefore such undesired action would occur ironically.

Wegner tested the ironic processes of mental control theory (1994) in a number of studies and provided considerable amount of evidence for the various areas of research for example; in thought suppression (Wegner \& Erber, 1992), mood control (Wegner, Erber, \& Zanakos, 1993), intentional relaxation (Wegner, Broome, \& Blumberg, 1997), intentional concentration (Wegner, 1997), control of sleep (Ansfield, Wegner, \& Bowser, 1996), and movement (Wegner, Ansfield, \& Pillof, 1998). In most of these studies, participants have shown a decrease in their performance (i.e., intention) when following an avoidant instruction (e.g., no to think or do something...) under high cognitive load. More specifically in the sports domain, Dugdale and Eklund (2003) conducted research by using a perceptual-motor control task (e.g., in well-learnt dancing skill) to examine the incidence of ironic effects. More specifically, the task required skilled dancers $(n=16)$ to balance on a wobble board for twenty seconds. The results showed that participants who were instructed "not to wobble" were significantly less stable than those who were instructed to "remain steady" on the wobble board.

Later, Woodman and Davis (2008) conducted a study in golf putting task $(n=58)$, specifically participants put a golf ball to a target, and were instructed "not to overshoot" of the target. Results of this study lend support to Wegner's (1994) notion that cognitive load increases the likelihood of the incidence of ironic errors in golf putting task. Results demonstrated that participants over put the golf ball by $35 \mathrm{~cm}$ when they urged not to hit the ball past the target. In a laboratory-based experimental study, Bakker, Oudejans, Binsch and Van der Kamp (2006) showed that experienced football players who were instructed to avoid aiming their kicks for penalty shootout at a particular part of the goal tend to direct their gaze at the very location to be avoided by using eye-tracking technology. Specifically, researchers found that when taking penalties in football, an approach of simply "not to miss" could ironically increase the likelihood that is precisely what will happen (Oudejans, Binsch, \& Bakker, 2013). Similarly, Binsch and colleagues (2010) investigated whether ironic effects in aiming are indeed accompanied by a shorter fixation on the target following negative and positive instructions. The result of their study also revealed that when participants were negatively instructed not to shoot closer to the goalkeeper, this resulted in them shooting closer and looking more to the keeper based on eye gaze examination.

More recently, Woodman, Barlow and Gorgulu (2015) conducted one of the most comprehensive research in ironic effects across two experimental studies and found that under anxiety provoking (e.g., combination of competition, financial incentives and social evaluation) conditions across two different studies of hockey penalty shooting $(n=40)$ and dart throwing task $(n=73)$ provided considerable support for the Wegner's (1994) theory of ironic processes of mental control. More specifically, Woodman and colleagues conceptualized an ironic error zone as the to-be-avoided zone and hockey players hit more shots into that zone under pressure to compare with no pressure. Similarly, in the second study, novices were asked to perform a dart throwing task under low- and high-anxiety conditions and the results provide support for the Wegner's (1994) theory that participants threw more darts into the to-be-avoided side of the dartboard called "ironic zone" under high-pressure conditions to compare with low-pressure condition (Woodman et al., 2015). Thus, research shows both practical importance and theoretical interest to understand how ironic processes of mental control and avoidant instructions operate in highly automatized tasks (Malhotra, Charlyon, Starkey, \& Masters, 2018) in sport such as dart-throwing, penalty shooting in football and hockey etc.

However, these sports-related ironic effect studies are mostly conducted in a laboratory setting with little relevance to the field sports. Therefore, to increase scientific rigor and ecological validity, the aim of the current study was to examine the effects of avoidant instructions on a basketball free throw task under different conditions (low and high-anxiety) which can be considered as a perceptual-motor task that requires attention regulation (e.g., Wilson et al., 2009). In a series of studies (Englert \& Bertrams, 2012; 2013); it was highlighted that performance in such tasks (e.g., perceptual-motor tasks; hand-eye coordination) moderated by the situational 
(e.g., important events, competition) available self-control related with anxiety (e.g., time pressure, task difficulty, importance of competition). Moreover, several studies have also demonstrated that a higher level of anxiety is associated with impaired performance in basketball free throw shooting (Wilson et al., 2009). However, it is unclear whether a participant's performance was decreased due to elevated anxiety and limited self-control or specifically due to an undesired action based on the instruction was given at that current moment (e.g., the last free throw shooting in the match).

In the present study, participants were given a set of neutral instructions to maintain their performance in a basketball free throw shooting task under normal training conditions (low-anxiety) and then manipulated high anxiety condition (e.g., competitive environment) similar to their competitive environment. As previously validated high cognitive load manipulation strategies such as financial incentive, competition, social evaluation (Gorgulu, 2017; Barlow, Woodman, Gorgulu, \& Voyzey, 2016; Woodman et al., 2015) can be used to manipulate and increase pressure in order to explore ironic effects under high cognitive load (e.g., anxiety). In order to test the effectiveness of those anxiety manipulation strategies, it was hypothesized that participants would produce more ironic errors when specifically asked "not to throw to the rim" under the high-anxiety condition to compare with the low-anxiety condition, thus the magnitude of the ironic error will be greater under pressure. Therefore, participants' overall performance scores would decrease from low-anxiety to high-anxiety conditions respectively. It was also hypothesized that participants would demonstrate no change in their throws to the non-ironic error zone on the target across anxiety conditions.

\section{Method}

\subsection{Participants}

37 male $\left(M_{\text {age }}=21.02, S D=2.48\right)$ experienced university basketball players $\left(\mathrm{M}_{\text {experience in years }}=8.74, S D=2.45\right)$ voluntarily participated in the current study. Basketball teams were approached and contacted with their coaches. After explaining the research study, the researcher agreed and organized the testing schedule with the head coach from three different teams. Other 2 teams were excluded from the study due to their unsuitable training schedule for the present research. All participants were asked and therefore reported being free from illness or injury at the time of the experiment day. The inform consent form was obtained from all participants and also from their head coaches of their university team. An institutional ethical approval was granted by the local institution for the present study.

\subsection{Measures}

Participants' anxiety was measured via self-report measure of MRF-3 (Krane, 1994) and their performance was measured using basketball free throw task.

\subsubsection{Anxiety}

The Mental Readiness Form-3 (MRF-3, Krane, 1994) used to measure participants' cognitive anxiety, somatic anxiety and self-confidence. The MRF-3, which comprises three single-item factors, requires participants to express how they feel right now by placing a mark from 1 to 11 on three separate $10 \mathrm{~cm}$ visual-analogue scales. From left to right the scales are anchored: not worried-worried (cognitive-anxiety); not tense-tense (somatic-anxiety); and not confident-confident (self-confidence). Thus, high scores represent high cognitive anxiety, high somatic anxiety and high self-confidence (Krane, 1994; Woodman et al., 2015).

\subsubsection{Performance}

Basketball free throw performance was measured at the participants training indoor facilities with their own equipment (e.g., ball, target). The task consisted of three distinct throws namely; the target throw, non-target non-error throw and non-target ironic error throw. Specifically, the target was making a successful shot without touching the rim that calls the Swish shot, non-target non-error was classified as hitting the ball anywhere on the board, finally and the most importantly the ironic error was classified as one of the two scenarios; first, hitting the rim or the board but missing the shot or having no contact with the basketball hoop at all. According to above classifications, participants scored +5 points for making a Swish shot (without touching the rim or the hoop), 0 point for hitting the ball anywhere on the board (whether it is a point or not), and scored -5 points for missing the shot by hitting the rim or the backboard (which is an ironic error) or having no contact with the basketball hoop at all.

\subsection{Procedure}

Participants took part in the current research individually and informed about the research upon entry to the indoor basketball court participants. Then they completed an informed consent and demographic information 
sheet (e.g., age, gender, level of current status in basketball, years of experience in basketball). Participants were allowed to warm up for 20 minutes before the experiment begin.

Participants then performed a series of basketball free throws from the free throw line (a distance of $4.60 \mathrm{~m}$ ) on a regular basket (height $3.04 \mathrm{~m}$ from the ground) with an official basketball game (Englert, Bertrams, Furley, \& Oudejans, 2015). The experiment consisted of 3 trials and 5 minutes break was given between each trial; first, 10 warm-up throws were given as a part of familiarization with the scoring system. Second, under low-anxiety condition 15 throws were given to participants and third 15 throws were given under high-anxiety condition. More specifically, participants were given an instructional set that "Please try to throw to the target (centre of the basket) and make the shot in order to get 5 points for each throw you do, however please be careful not to miss the shot (by either hitting the rim or the board or not having a contact with the hoop at all) as you will score minus five points for each ball you do and finally participants were instructed that if they make the point by hitting the rim or the board this will score zero points for each ball you do".

Upon completion first trial (warm-up) participants responded to the MRF-3 and then performed 15 throws under the low-anxiety conditions in the second trial. Participants followed the same procedure in the last trial with one exception that before completing the MRF-3, participants were informed that they were about to enter the competition by participating in the third trial and based on the results of this last trial, the highest scorer would receive 250 Turkish Liras (approximately US \$50) immediately at the end of the experiment as a part of the competition. The aim was to manipulate anxiety using multiple ecologically valid performance stressors (i.e., competitive environment, financial incentive, and social evaluation; Bell \& Hardy, 2009; Barlow et al., 2016; Woodman et al., 2015) in order to create pressure situation similar to their official competition. Then they performed 15 throws under the high-anxiety condition. Each participant finalised the serving task individually. Additionally, they were informed that their scores during the performance were observed as beyond controversy while entering one of the three distinct areas. Finally, participants were thanked; debriefed and informed them to be announced the scores to all participants at the end of the study.
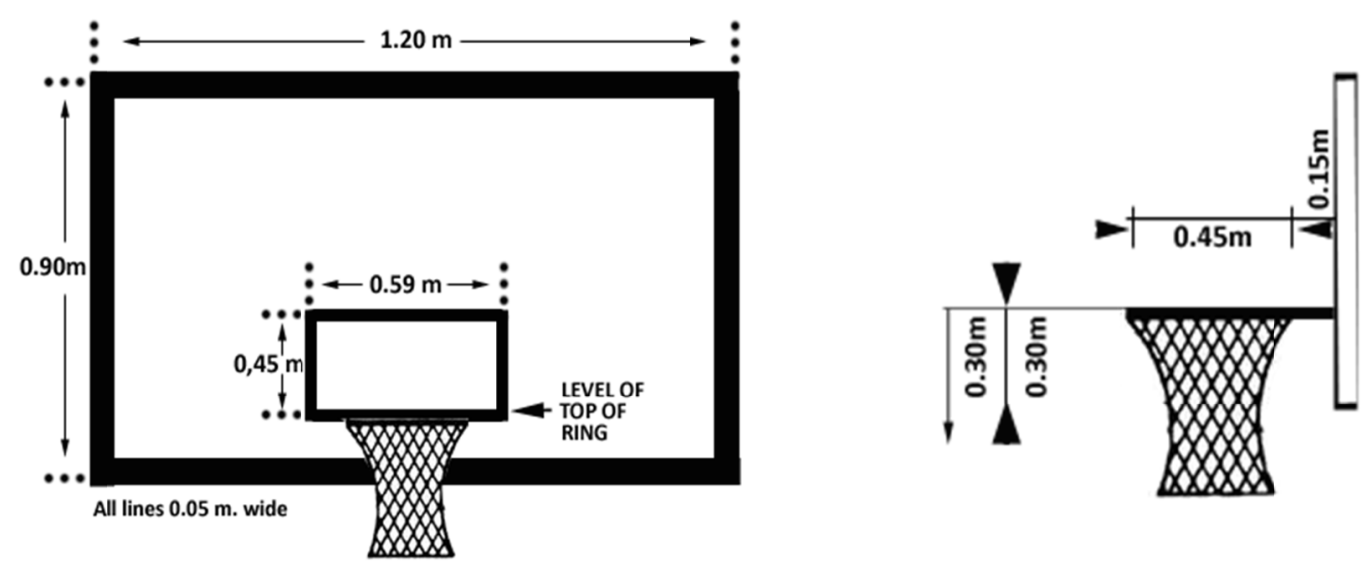

Figure 1. Experimental dimensions of the backboard and the rim

\section{Results}

\subsection{Anxiety Manipulation}

The measures of self-report MRF-3, heart rate and heart rate variability analysis confirmed the effectiveness of the anxiety manipulation check. Results revealed that cognitive anxiety $(t 36=3.15, p<.001)$, somatic anxiety $(t 36=3.21, p<.001)$ and self-confidence $(t 36=6.85, p<.001)$ from low- to the high-anxiety condition. The results for the anxiety manipulation check summarized in Table 1. 
Table 1. Descriptive statistics confirming the effectiveness of the anxiety manipulation of the study

\begin{tabular}{llll}
\hline & \multicolumn{2}{l}{ Condition } & \\
\cline { 2 - 3 } Measure & Low-Anxiety & High-Anxiety & $t(36)$ \\
& Mean $(\mathrm{SD})$ & Mean $(\mathrm{SD})$ & $5.66^{* * *}$ \\
Cognitive-anxiety & $4.75(2.29)$ & $7.86(2.09)$ & $5.70^{* * *}$ \\
Somatic-anxiety & $5.43(2.37)$ & $8.18(1.82)$ & $2.79^{* * *}$ \\
Self-confidence & $6.70(1.59)$ & $4.48(1.72)$ & \\
\hline
\end{tabular}

Note. $* * * \mathrm{p}<.001$. Cognitive-anxiety, Somatic-anxiety and Self-confidence were measured via MRF-3 (Krane, 1994).

\subsection{Performance}

A 2 (anxiety: low, high) x 3 (ironic error zone, target zone, non-ironic error zone) fully repeated measures of ANOVA was conducted to analyse performance. The sphericity assumption was violated, thus the Greenhouse-Geisser correction factor to the degrees of freedom was applied. Results revealed a significant main effect for anxiety $F(1,36)=14,17, p=.001, \eta 2=.28$ a significant main effect for zone, $F(1,36)=48,12, p=.001$, $\eta 2=.57$ and a significant anxiety x zone interaction $F(2,72)=8,47, p=.05, \eta 2=.19$. Bonferroni-corrected follow up paired samples $t$-tests revealed that participants threw significantly fewer balls into the basket as the target $(t 36=4.71, p<.001)$, significantly more balls in the ironic error zone $(t 36=-7.57, p<.001)$ and overall significantly scored lower points $(t 36=5.00, p<.001)$ as hypothesized. However, there was no significant difference in non-target non-ironic error across anxiety conditions $(t \mathbf{s}<1, p \mathrm{~s}>.5)$.

Table 2. Mean number of basketball free throws in the target zone, ironic zone and non-target non-ironic error zone under low-and manipulated high-anxiety conditions

\begin{tabular}{|c|c|c|c|}
\hline \multirow[b]{2}{*}{ Measure } & \multicolumn{2}{|l|}{ Condition } & \\
\hline & Low-Anxiety & High-Anxiety & \\
\hline & Mean (SD) & Mean (SD) & $t(36)$ \\
\hline Target Zone (1) & $7.05(1.59)$ & $5.81(1.57)$ & $4.71 * * *$ \\
\hline Non-target ironic error (2) & $3.64(1.58)$ & $5.21(1.47)$ & $-7.57 * * *$ \\
\hline Non-target non-ironic error (3) & $4.29(1.43)$ & $3.97(1.51)$ & 1.37 \\
\hline Performance (in points)* & $17.02(14.21)$ & $4.73(12.96)$ & $5.00^{* * *}$ \\
\hline
\end{tabular}

Note. $* * * \mathrm{p}<.001 . \quad=$ number of free throws were counted. $*=$ number of points was counted.

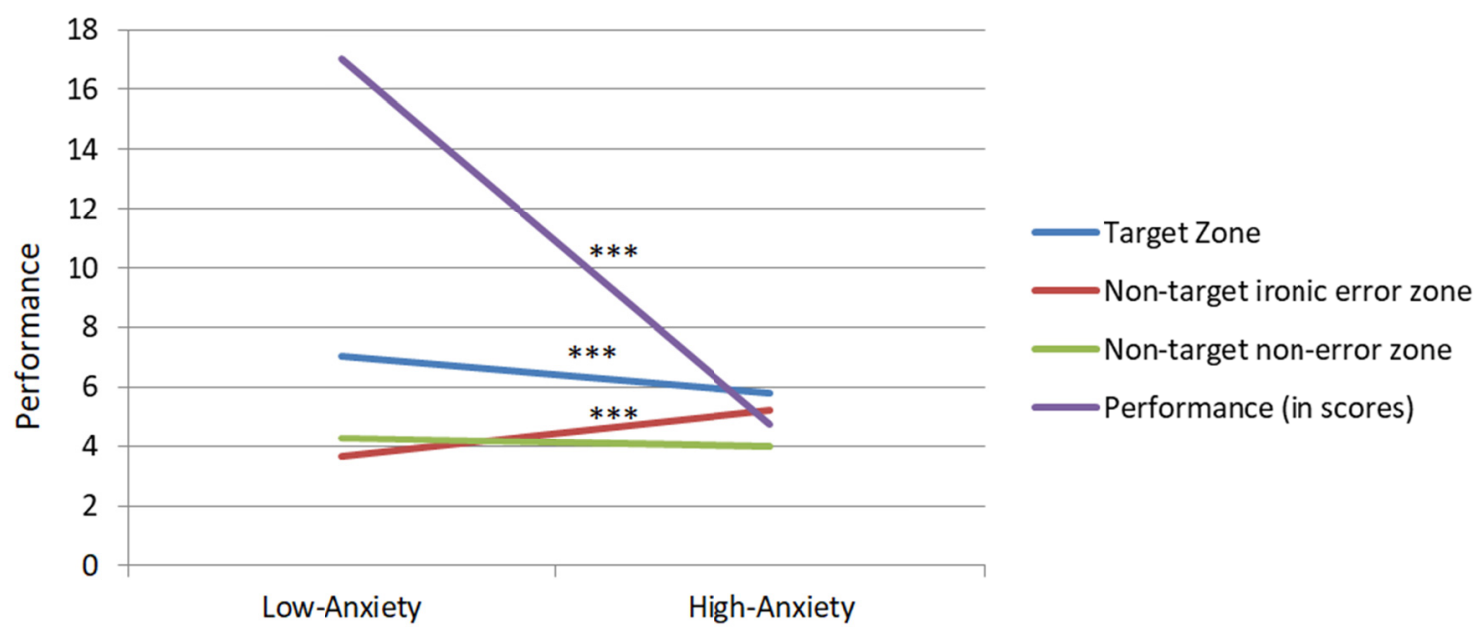

Figure 2. Mean number of target zone, non-target ironic error zone, non-target non-error zone and performance scores from low-anxiety to high-anxiety conditions

\section{Discussion}

The purpose of the present study was to examine Wegner's (1994) theory of ironic processes of mental control in an ecologically valid a basketball free throw task. According to Wegner's (1994) theory, participants' 
performance was examined under manipulative conditions (e.g., low- and high-anxiety) with the increased mental load in order to tax participants' cognitive resources. Notwithstanding concerns about the efficacy of artificially manipulating anxiety in laboratory-based research studies (e.g., Williams, Vickers, \& Rodriques, 2002; Wilson, Vine, \& Wood, 2009), the present field-based study provides support for the effectiveness of the manipulation check in elevating worry (see Table 1). In the present study, the university basketball players were elite free throw shooters with a high percentage of shooting accuracy (Harle \& Vickers, 2001). In line with studies that used novices (e.g., dart throwing, university hockey players) to test ironic effects, the current results provided support for the Wegner's (1994) theory when experienced participants instructed not to throw the ball in a certain part of the basketball hoop especially under manipulated high anxiety condition that they did so a significantly greater number of times (see Table 2). Most importantly, there was no difference in non-ironic error and in target throws across anxiety conditions. The results of the current study suggest that the influence of anxiety on performance, through impairments in cognitive capacity is not just an important issue for novices or lower level of performers (Wilson et al., 2009; Woodman et al., 2015) but also elite and experienced performers too.

Previous research (Wine, 1971; 1980) hypothesized that one's performance will suffer when cognitive anxiety is elevated as the cognitive capacity is taken up with undesired thoughts associated with anxiety (e.g., don't throw the ball to the rim). Similarly, cue utilization theory predicts that performers would perform better when they are recalling only task relevant cues beforehand (Easterbrook, 1959). However, partipants in the present study demonstrated such a decrease in their performance when they were specifically instructed "not to throw to the cerain part of the backboard" (e.g., when given negative instruction under pressure) which provides support for the Wegner's (1994) theory. Since Wegner's (1994) theory remains unique - in the assertion that performance when anxious will break down in a precisely counter-intentional manner-it continues to hold interest for researchers and potential significance for research examining the anxiety-performance relationship in different context. For example, Woodman and colleagues (2015) reported that performers threw fewer darts in the target zone and more darts in the to-be-avoided zone namely ironic error zone under high anxiety conditions. Due to the increased errors on the target throws, one could argue that our results might reflect general performance deterioration rather than uniquely counter-intentional errors during high-anxiety condition. However, the current study found similar results with one exception that is basketball players' target throws did not change as well as the non-target non-ironic error rates across anxiety conditions. More specifically, for aiming type of tasks such as basketball free throw, dart throwing, pistol shooting, a particular fixation termed the quiet eye (Vickers, 1996), defined as the final fixation to a target before the initiation of the motor response (Badau, Baydil, \& Badau, 2018), can become less efficient while performer has to perform under pressure. Therefore, taking a deep breath and not to hurry could allow performers an extended duration of programming while minimizing distractive or unwanted thoughts. Within the current study, there are some limitations that could be addressed by future research. The sample size is not optimum for the medium population effect size and the $95 \%$ significance level used in the present study. Another factor that is worth considering is the effect of self-confidence on the incidence of ironic errors. Although it was not the main aim of measuring self-confidence as a manipulation check or indication of anxiety, participants reported significantly lower levels of self-confidence under elevated anxiety condition. Specifically, this could be controlled by comparing participants who reported a lower and high level of self-confidence under the low-anxiety condition in a between-subjects design. Similarly, gender difference comparison is another area to pay attention to future research in the incidence of ironic effects. For example, Weinberg and Gould (2003) stated that females are more susceptible to report a lower level of self-confidence than males that would provide a comprehensive understanding of individuals who required performing under pressure. This would enable analyses of whether such gender differences would have an impact on the incidence of ironic effects or not.

Overall, the current study shed light on the type of training and the way the coaches and educators use their instructions. First, players should be trained systematically and periodically under a certain degree of pressure in order to test their different skills and prepare them for such a competitive environment. The second strategy would be to modify coaching instructions for the critical moments and for specific tasks or targets especially when performers under the condition of high pressure. Researchers (Wegner et al., 1998; Woodman \& Davis, 2008) have previously measured counter intentional errors in sport and motor control studies (Gorgulu, 2019) on a single or numerous trial (Woodman et al., 2015), in line the present research shows the aim of attempting to capture ironic effect in a more robust and meaningful results for performers who are required to perform well under pressure. Other approaches could also be worth considering, for example, Woodman and colleagues (2015) suggest that cognitive behavioural interventions could use to decrease the performer's performance interfering thoughts (Sarason, Pierce, \& Sarason, 2009) have previously been shown to enhance sporting performance (e.g., 
Meyers, Whelan, \& Murphy, 1996). Results emanating from the current study could be applied to exercise and fitness domain in order to help to increase body perception and improve exercise dependence attitudes (Badau, \& Badau, 2018) by using appropriate words and instructions when setting goals for exercise participants who might feel under pressure in especially at fitness environment. As a result, the current study suggests that such training programmes mentioned above may also be a useful intervention to enhance performance under pressure, specifically not to allow unwanted thoughts to break down performance in a way where it is least desired. Although results of the present study have provided some replicative evidence of previous research (e.g., Woodman et al., 2015) which supports Wegner's (1994) theory, future research should continue to investigate the mechanisms of performance breakdown at different level of expertise and sports that may be more relevant to understand anxiety-performance relationship in other contexts.

\section{Acknowledgments}

The author would like to thank participants who voluntarily accept and participated in the current study and also their coaches for their help and valuable time over the course of data collection.

\section{References}

Ansfield, M., Wegner, D. M., \& Browser, R. (1996). Ironic effects of sleep urgency. Behaviour Research and Therapy, 34, 523-531. https://doi.org/10.1016/0005-7967(96)00031-9

Badau, D., \& Badau, A. (2018). Identifying the Incidence of Exercise Dependence Attitudes, Levels of Body Perception, and Preferences for Use of Fitness Technology Monitoring. Int. J. Environ. Res. Public Health, $15,2614$.

Badau, D., Baydil, B., \& Badau, A. (2018). Differences among Three Measures of Reaction Time Based on Hand Laterality in Individual Sports. Sports, 6(2), 45.

Bakker, F. C., Oudejans, R. R. D., Binsch, O., \& Van der Kamp, J. (2006). Penalty shooting and gaze behavior: Unwanted effects of the wish not to miss. International Journal of Sports Psychology, 37, 265-280.

Barlow, M., Woodman, T., Gorgulu, R., \& Voyzey, R. (2016). Ironic effects of performance are worse for neurotics. Psychology of Sport and Exercise, 24, 27-37. https://doi.org/10.1016/j.psychsport.2015.12.005

Baumeister, R. F. (1984). Choking under pressure: Self-consciousness and the paradoxical effects of incentives on skilled performance. Journal of Personality \& Social Psychology, 46(3), 610-620. https://doi.org/10.1037/0022-3514.46.3.610

Bell, J. J., \& Hardy, J. (2009). Effects of attentional focus on skilled performance in golf. Journal of Applied Sport Psychology, 21, 163-177. https://doi.org/10.1080/10413200902795323

Binsch, O., Oudejans, R. R. D., Bakker, F. C., Hoozemans, M. J. M., \& Savelsbergh, G. J. P. (2010). Ironic effects in a simulated penalty shooting task: Is the negative wording in the instruction essential? International Journal of Sport Psychology, 41, 118-133.

Dugdale, J. R., \& Eklund, R. C. (2003). Ironic processing and static balance performance in high-expertise performers. Research Quarterly for Exercise and Sport, 74(3), 348-352. https://doi.org/10.1080/02701367.2003.10609102

Easterbrook, J. A. (1959). The effect of emotion on cue utilization and the organization of behavior. Psychological Review, 66(3), 183-201. https://doi.org/10.1037/h0047707

Englert, C., \& Bertrams A. (2012). Anxiety, ego depletion, and sports performance. Journal of Sport and Exercise Psychology, 34, 580-599. https://doi.org/10.1123/jsep.34.5.580

Englert, C., \& Bertrams A. (2013). Too exhausested for Operation? Anxiety, depleted self-control strength, and perceptual motor performance. Self and Identity, 12, 650-662. https://doi.org/10.1080/15298868.2012.718865

Englert, C., Bertrams, A., Furley, P., \& Oudejans, R. (2015). Is ego depletion associated with increased distractibility? Results from a basketball free throw task. Psychology of Sport and Exercise, 18, 26-31. https://doi.org/10.1016/j.psychsport.2014.12.001

Eysenck, M. W., Derakshan, N., Santos, R., \& Calvo, M. G. (2007). Anxiety and cognitive performance: Attentional control theory. Emotion, 7(2), 336-353. https://doi.org/10.1037/1528 3542.7.2.336

Gorgulu, R. (2017). An Examination of the Precise Nature of Ironic Performance Breakdown. PhD thesis, Priyfsgol Bangor University. 
Gorgulu, R. (2019). Ironic and Overcompensation Effects of Motor Behaviour: An Examination of a Tennis Serving Task Under Pressure. Behavioral Sciences, 9, 21. https://doi.org/10.3390/bs9020021

Hardy, L. (1990). A catastrophe model of performance in sport. In J. G. Jones \& L. Hardy (Eds), Stress and Performance in Sport (pp. 81-106). Chichester, UK: John Wiley \& Sons. https://doi.org/10.1111/j.2044-8295.1991.tb02391.x

Hardy, L., Beattie, S., \& Woodman, T. (2007). Anxiety-induced performance catastrophes: Investigating effort required as an asymmetry factor. British Journal of Psychology, 98(1), 15-31. https://doi.org/10.1348/000712606X103428

Hardy, L., Woodman, T., \& Carrington, S. (2004). Is self-confidence a bias factor in higher order catastrophe models? An exploratory analysis. Journal of Sport and Exercise Psychology, 26(3), 359-368. https://doi.org/10.1123/jsep.26.3.359

Harle, S., \& Vickers, J.N. (2001). Training quiet eye improves accuracy in the basketball free-throw. The Sport Psychologist, 15, 289-305. https://doi.org/10.1123/tsp.15.3.289

Krane, V. (1994). The Mental Readiness Form as a measure of competitive state anxiety. The Sport Psychologist, 8(2), 189-202. https://doi.org/10.1123/tsp.8.2.189

Malhotra, N., Charlton, S., Starkey, N., \& Masters, R. (2018). Examining Ironic Processes in Tourist Drivers: Driving on the Unfamiliar Side of the Road. Safety, 4(3), 28, 1-13. https://doi.org/10.3390/safety4030028

Masters, R. S. W. (1992). Knowledge, knerves and know-how: The role of explicit versus implicit knowledge in the breakdown of a complex motor skill under pressure. British Journal of Psychology, 83(3), 343-358. https://doi.org/10.1111/j.2044-8295.1992.tb02446.x

Meyers, A., Whelan, J., \& Murphy, S. (1996). Cognitive behavioral strategies in athletic performance enhancement. Progress in Behavior Modification, 30, 137-164.

Oudejans, R. D., Binsch, O., \& Bakker, F. C. (2013). Negative instructions and choking under pressure in aiming at a far target. International Journal of Sport Psychology, 44, 294-309. https://doi.org/10.1080/10615806.2010.481331

Sarason, I. G., Pierce, G. R., \& Sarason, B. R. (2009). Cognitive interference: Theories, methods, and findings. London, UK: Routledge.

Vickers, J. N. (1996). Visual control when aiming at a far target. Journal of Experimental Psychology, Human Perception and Performance, 2, 324-354. https://doi.org/10.1037/0096-1523.22.2.342

Wegner, D. M. (1997). Why the mind wanders. In J. D. Cohen \& J. W. Schooler (Eds.), Scientific approaches to consciousness (pp. 295-315). Mahwah, NJ: Erlbaum.

Wegner, D. M., \& Erber, R. (1992). The hyperaccessibility of suppressed thoughts. Journal of Personality and Social Psychology, 63, 903-912. https://doi.org/10.1037/0022-3514.63.6.903

Wegner, D. M., Ansfield, M. E., \& Pilloff, D. (1998). The putt and the pendulum: Ironic effects of the mental control of action. Psychological Science, 9(3), 196-199. https://doi.org/10.1111/1467-9280.00037

Wegner, D. M., Broome, A., \& Blumberg, S. J. (1997). Ironic effects of trying to relax under stress. Behaviour Research and Therapy, 35, 11-21. https://doi.org/10.1016/S0005-7967(96)00078-2

Wegner, D. M., Erber, R., \& Zanakos, S. (1993). Ironic processes in the mental control of mood and moodrelated thought. Journal of Personality and Social Psychology, 65, 1093-1104. https://doi.org/10.1037/0022-3514.65.6.1093

Weinberg, R. S., \& Gould, D. (2003). Foundations of Sport and Exercise Psychology (3rd ed.). Champaign, IL: Human Kinetics.

Williams, A. M., Vickers, J. N., \& Rodrigues, S. T. (2002). The effects of anxiety on visual search, movement kinematics, and performance in table tennis: A test of Eysenck and Calvo's processing efficiency theory. Journal of Sport \& Exercise Psychology, 24, 438-455. https://doi.org/10.1123/jsep.24.4.438

Wilson, R. M., Vine, J. S., \& Wood, G. (2009). The influence of anxiety on visual attentional control in basketball free throw shooting. Journal of Sport \& Exercise Psychology, 31, 152-168. https://doi.org/10.1123/jsep.31.2.152

Wine, J. (1971). Test anxiety and direction of attention. Psychological Bulletin, 76(2), 92-104. https://doi.org/10.1037/h0031332 
Wine, J. (1980). Cognitive-Attentional Theory of Test Anxiety. In I. G. Sarason (Ed.), Test Anxiety: Theory, Research and Applications (pp. 349-385). Hillsdale, NJ: Erlbaum.

Woodman, T., \& Davis, P. A. (2008). The role of repression in the incidence of ironic errors. The Sport Psychologist, 22, 184-197. https://doi.org/10.1123/tsp.22.2.183

Woodman, T., Barlow, M., \& Gorgulu, R. (2015). Don't miss, don't miss, d'oh! Performance when anxious suffers specifically where least desired. The Sport Psychologist, 29(3), 213-223. https://doi.org/10.1123/tsp.2014-0114

\section{Copyrights}

Copyright for this article is retained by the author, with first publication rights granted to the journal.

This is an open-access article distributed under the terms and conditions of the Creative Commons Attribution license (http://creativecommons.org/licenses/by/4.0/). 